\title{
COMMISSION 22: METEORS \& INTERPLANETARY DUST
}

(Météores et poussière interplanétaire)

PRESIDENT: I.P.Williams

VICE-PRESIDENT: W. J. Baggaley

SECRETARY: R. L. Hawkes

ORGANISING COMMITTEE: P.B.Babadzhanov, Z. Ceplecha, E. Grün, I. Hasegawa,

J. Jones, C. Koeberl, V. Porubčan and D. I. Steel.

\section{INTRODUCTION}

As has been the usual practice for a number of years in Commission 22, members of the commission with expertise in different areas have prepared contributions reviewing their own fields and these have been consolidated by the President and Secretary to form the report as it appears below. Over the past triennium there have been a number of conferences and meetings concerned either solely with meteors and/or interplanetary dust or include these subjects amongst the topics covered, in fact too many, especially in the latter category, to list in detail. Many of the papers referenced below are from the proceedings of those conferences and these proceedings may also contain other papers, not specifically referenced in the reviews, that may nevertheless be of interest to commission members. Specific conferences in which members of Commission 22 have played a major part were the following:

IAU Symposium 160, Asteroids Comets Meteors 1993: Belgirate, Italy, 1993 June (Reviews now published Milani, Di Martino and Cellino, 1994, contributed papers in a number of issues of Planetary and Space Science) (This meeting was strictly outside the review period which starts on 1993 July 1, but the proceedings and indeed the meeting impact, are both within the period)

Worlds in Interaction: Small Bodies and Planets of the Solar System. Mariehamn, Auland, 1994 August 8-14 (Proceedings now published as Earth, Moon, and Planets, 72, 1996)

Meteoroids. Bratislava, Slovakia, 1994 August 28-31 (Proceedings now published as Earth, Moon, and Planets, 68, 1995)

IAU Colloquium 150, Physics, Chemistry, and Dynamics of Interplanetary Dust, Gainesville, Florida, USA, 1995 August 14-18 (Proceedings published as a proceedings by the Astronomical Society of the Pacific, editors B.A.S Gustafson and M. Hanner).

Asteroids, Comets, Meteors, 1996, Versailles, France, $1996 \mathrm{July}$ 8-12 (Reviews to be published as a single volume, contributed papers to appear in a special volume of Planetary and Space Science).

Commission 22 has established a WWW home page at

http://aci.mta.ca/TheUmbrella/Physics/Meteor/IAU22

This contains an email directory, links to other IAU pages, lists of conferences and publications of interest to commission members, and links to home pages of national and international meteor organizations and individual researchers. In addition to a printed newsletter, the commission has also sent out electronic notices. To be added to the electronic distribution list, send an email message to rhawkes@mta.ca.

Commission 22 currently has representatives on two inter-commission Working Groups, The Prevention of Interplanetary Pollution (Chair C. S. L. Keay of Commission 22, representatives being Z. Ceplecha and D. I Steel) and Near-Earth Objects (Chair A. Carusi of Commission 20, Commission 22 representatives being D.I. Steel and I.P. Williams). Both these Working Groups have produced their own reports which can be found elswhere in this volume. The Commission has also one Working Group of its own, Amateur-Professional Co-operation in Meteors, consisting of R.L. Hawkes (Chair), V. Porubčan, D.I. Steel, J. Mason, A. Terentieva, I. Hasegawa, P. Brown, P. Roggemans, T.Yoshida, D. Očenáš, J. Rendtel, J. Woods. This group has met twice over the past triennium, with discussion of ways to improve coordination between the amateur and professional meteor communities. The electronic mailing list (which goes to both professional and amateur meteor researchers) and the IAU Commission 22 WWW pages were developed to link professional and amateur researchers and organizations. There was also discussion of the need for a standardized list of meteor showers, although the International Meteor Organization and the Dutch Meteor Society have both recently updated and published on the WWW lists which now meet this need. 


\section{PHOTOGRAPHIC METEORS, FIREBALLS AND SPECTROSCOPY J.BOROVIČKA and P.SPURNÝ}

The European Fireball Network remains the only professional continuously operated photographic system for meteor observation. The summary data for the 17 most prominent fireballs photographed in 1990-1993 have been published by Spurný (1994). A similar list for the period 1993-1996 is now in preparation. Reports on individual fireballs are being continuously published in the WGN journal. The data on Perseids with the emphasis to the 1993 peak activity are given in Spurný (1995). More meteor data can be obtained from P. Spurný on request. The quality of the results has been improved by using a new astrometric method for all-sky cameras (Borovička et al. 1995).

Halliday et al. (1996) published detailed data for 259 fireballs photographed by the Canadian MORP network in 1971-1985. 213 events represent an unbiased sample of the clear-sky survey and enabled a statistical study of the influx of large meteoroids. The research indicates that 46 fireballs are probable meteorite droppers.

Amateur observers of the Dutch Meteor Society and several groups in Japan continue to obtain good photographic data, especially on shower meteors. Their results as well as many older data are available from the IAU Meteor Data Center in Lund (Linblad and Steel 1994, Linblad 1995). The Dutch data are available also on Internet, at http://www.pi.net/terkuile/meteors/dms-www/orbits.htm. The observations of fireballs are being gathered and published by the Fireball Data Center of the International Meteor Organization (Knöfel 1995).

Probably the most exciting progress in fireball observation has been availability to the scientific community fireball data from military satellites. There are two kinds of detectors, visible and infrared, described in Tagliaferri et al. (1994). They are sensitive only to very bright events (magnitude about -20 and brighter) but operate on a global scale and are therefore able to monitor impacts of meter-sized and larger bodies, rarely captured by local photographic networks. The most prominent event recorded up to now was the Marshall Islands Fireball of February 1, 1994 (Tagliaferri et al. 1995, McCord et al. 1995).

The video records of the 1992 October 9 Peekskill fireball associated with a meteorite fall have been analyzed and the fireball trajectory and orbit have been determined (Brown et al. 1994, Ceplecha et al. 1995, Beech et al. 1995b). Peekskill therefore became the fourth meteorite with a precisely known heliocentric orbit. The analysis of the atmospheric fragmentation and other details is still continuing. Another meteorite fall occurred in St. Robert, Canada on June 15, 1994. Apart from the visual observations, the fireball was recorded also by satellite detectors which enabled inferences on its trajectory and mass to be made (Brown et al. 1996). A very bright bolide exploded over North Italy on January 19, 1993. It was recorded by a forward scatter radar, by five seismic stations and recondensed microspherules have been collected on the ground (Cevolani 1994, Korlević and Valdré 1994).

A detailed analysis of two older very bright photographic fireballs was published by Borovička and Spurný (1996). The light curves, spectra, and dynamics were studied. The different behavior of cometary and asteroidal bodies was demonstrated, the importance of fragmentation in both cases was shown and the role of continuous radiation in the spectra of bright fireballs was revealed for the first time. Meisel $e t$ al. (1995) reported a bolide observation with various techniques. However, their conclusions about the meteoroid composition based on the recorded infrared spectrum are not correct in our opinion.

Ceplecha (1994a) published a survey of 14 scientifically observed fireballs corresponding to impacts of meteoroids larger than 1 meter. Note, however, that the mass scale was determined using the old value of luminous efficiency and the meteoroid sizes are therefore generally overestimated. The new value of luminous efficiency valid for bodies in $100 \mathrm{~kg}$ range was found by Ceplecha (1996) by a detailed study of the Lost City meteorite fall to be up to 10 times larger than the old value derived for smaller bodies. The new mass scale also led Ceplecha (1996) to refine the value of the total mass influx onto Earth to $1.5 \times 10^{8} \mathrm{~kg}$ per year.

In analog with the luminous efficiency, ReVelle and Whitaker (1995) studied the acoustic efficiency of fireballs using infrasound detections. They found typical values of 0.1 to $7 \%$. Keay and Ceplecha (1994) and Keay (1995) continued the investigation of electrophonic sounds of fireballs. Beech et al. (1995a) reported a detection of a VLF radio signal of a bright fireball.

The fireball optical spectrum analysis described in the previous report was published (Borovička 1993, 1994a). In addition Borovička (1994b) studied two components of different temperature in meteor spectra. Individual meteor spectra were described by Ridley (1994), Borovička and Zamorano (1995) 
and Borovička and Spurný (1996). The first results from the TV spectroscopy of faint meteors at the Ondřejov observatory are given in Borovička and Boček (1995). Rajchl et al. (1995) and Borovička et al. (1996) studied the spectra of long enduring meteor trains. The forbidden lines of ionized atoms were identified in the latter case.

Smirnov (1995) theoretically studied the relation between the particle distribution in the meteor plasma and the meteor spectrum. Coradini et al. (1994) performed a laboratory simulation of satellite atmospheric re-entry to study the spectrum of such an event. It was found that the emissions of the fragment material dominate the spectrum.

Meteor observations were used by several authors to derive meteoroid properties such as density and fragmentation (Babadzhanov 1994, Ceplecha et al. 1993, Ceplecha 1994b, Kalinichenko 1995, Lebedinets and Galkina 1995, Novikov et al. 1996). Borovička (1994c) discussed the possibility of determining meteoroid composition from meteor spectra. One diogenite meteoroid was identified and its heliocentric orbit determined. ReVelle and Ceplecha (1994) developed two techniques of identifying iron meteoroids from non-spectral meteor data. They found 7 probable irons among 287 fireballs.

An analytical description of meteoroid entry was presented by Celnikier (1995) and McInnes (1995). Adolfsson and Gustafson (1994) studied the effect of meteoroid rotation on meteor beginning height. Meteoroid rotation was discussed also by Kruchinenko (1995). Zakharov and Karpenko (1993) studied the radiative heating of porous meteoroids. Bellot Rubio (1995) discussed the dependence of meteor brightness on the entry angle in connection with the determination of meteor shower activity. Adolfsson et al. (1996) showed that meteors would be observable from the surface of Mars.

Theoretical models of atmospherical disintegration of large meteoroids were presented by Svetsov et al. (1995) and also by Bronshten (1994). Fireball radiation was modeled by Nemtchinov et al. (1994, 1995). Several papers were devoted to the prediction of the behavior of the nuclei of comet ShoemakerLevy 9 on entry into Jupiter atmosphere. While Sekanina (1993) applied the experience with terrestrial meteors, others developed theoretical models, both analytical and numerical (Crawford et al. 1994, Zahnle and MacLow 1994, MacLow and Zahnle 1994, Takata et al. 1994, Chevalier and Sarazin 1994, Field and Ferrara 1995, Svetsov 1995). The results of different authors are different and the debate is still continuing at the moment. The comparison of observational evidence on bright meteors with theoretical models has been given in Ceplecha (1995) and Borovička and Spurný (1996).

\section{RADAR METEORS}

\section{W.G. ELFORD and A.D. TAYLOR}

Radar observations of meteors have been highlighted by two new technical developments: (a) the pulse by pulse measurement of the phase of VHF radar echoes, and (b) the detection of meteoric ionization using incoherent scatter at UHF. The former has been shown by Elford et al. (1995) to yield the speed of trail formation with unprecedented precision.

The UHF echoes have been observed with the Arecibo system (Zhou et al. 1995) and with the EISCAT radar (Pellinen-Wannberg and Wannberg 1994, 1996); the latter radar obtained incoherent scatter at heights up to $160 \mathrm{~km}$ from what is considered to be ion-acoustic waves in the meteoric plasma. Both UHF systems have detected down-the beam head echoes, and to explain the observed radar crosssections, Wannberg and Pellinen-Wannberg (1996) have invoked scattering from compact balls of plasma within the meteor coma. Forward-scatter studies have been continued over two $700 \mathrm{~km}$ baselines in Europe (Bologna-Lecce and Bologna-Modra). Cevolani et al. (1993a, 1993b) made several studies of the distribution of underdense echoes as a function of signal strength. Observations during the Lyrid shower of April 1993 (Hajduk et al. 1995) show that the echo rate for both underdense and overdense meteors is enhanced when the trails are oriented parallel to the baseline. From observations during the Perseids of 1991 and Quadrantids of 1992, Cevolani and Hajduk (1993) conclude that when meteor radiants are near the zenith the forward scatter tends to occur from the head of a trail. Observations of the Leonids in 1994 by Foschini et al. (1995) showed mainly underdense echoes, with overdense trails being detected several days after the expected peak of activity.

Jones et al. (1994) and Mawrey and Broadhurst (1993) used forward-scatter observations in Canada and South Africa to derive a model of the sporadic radiant distribution. Jones and Brown $(1993,1994)$ derived a sporadic radiant distribution from orbit data available in the IAU Meteor Data Centre; the distribution is consistent with the results of the forward- scatter observations. Elford (1993) pointed out that Faraday rotation during daytime can significantly reduce the detection rate of meteors observed both 
with backscatter and forward-scatter systems. A full description of the AMOR facility for measuring orbits has now appeared (Baggaley et al, 1994); the system is capable of yielding 1500 orbits per day with a limiting magnitude of +13 . Almost $1 \%$ of the meteoroids have speeds in excess of $100 \mathrm{~km} / \mathrm{s}$ (Taylor et al. 1994) and the majority of these particles are claimed to be interstellar (Baggaley et al. 1993a). From the intra-annual flux of these particles it is inferred that there are at least two discrete sources, one associated with nearby A-type stars, and the other with the Sun's motion about the Galactic Centre (Taylor et al. 1996).

Simek $(1994 a, b)$ used rate data collected with the Ottawa megawatt radar in October 1985 to derive the activity profile of the Giacobinid shower and interpreted the results as evidence for filamentary structure in the stream. Porubčan et al. $(1993,1994 a)$ used the Budrio radar to collect rate data for the 1986 Geminids and the 1986 Ursids. Porubčan et al. (1994b) compared rate data from the Geminids obtained with the Budrio and Springhill radars to examine the sunrise effect on meteor echo rates and ranges. Five southern hemisphere showers, Virginids, Corona Australids, $\alpha$ Scorpids, Ophiuchids and $\alpha$ Capricornids were detected in 1990 with the Newcastle meteor radar (Rogers and Keay, 1993). Sidorov et al. (1994) measured the radiant of the 1985 Draconids and the mass distribution of the particles.

Some VHF radars designed for study atmospheric dynamics, have been adapted to record meteor echoes. Watanabe (1993) used the MU radar near Kyoto to determine the activity of the 1991 Perseids. Elford et al. (1994) and Cervera et al. (1993) used the pencil-beam VHF radar near Adelaide to detect the 1992 June Librids by exploiting the high resolution characteristics of the response function for this system.

Andreev et al. (1993) examined the distribution of the orbital elements of meteoroids derived from radar observations, and showed that the distribution is deficient in meteors of high and low velocities. Taylor (1995) showed that the velocity distribution derived from the Harvard Radio Meteor Project had a gross numerical error, and that, when corrected, the velocity distribution is close to that derived from photographic observations. Jones (1995a) showed that the initial radius of meteor trails has a high density core and examined the consequences for the interpretation of radar meteor echoes.

\section{TELEVISION METEORS}

\section{R.L. HAWKES}

The most significant video meteor observational investigation during the past three year period was the extensive two station study by Ueda and Fujiwara (1995) (from Japan) which provides complete orbital data as well as atmospheric trajectory information for 265 meteors (326 meteors were partially analysed) down to +7 absolute magnitude. In addition to a large number of sporadic meteors, at least a few members of 13 meteor showers ( 5 apparently not previously detected) were observed, with significant representation of the $\eta$ Aquarid, Leonid, and Geminid showers. The paper compares the observed radiant distribution with predictions from cometary and near earth asteroids, although one must be wary of observational selection effects (single latitude of observations, concentration of data from the fall months). Another detailed two station study was that by de Lignie and Jobse (1996) who provided trajectory and orbital information for 29 Quadrantid and 20 sporadic meteors. Suzuki et al. (1994a) made a convincing case (using orbital determinations from double station television observations) for detection of a new shower active in mid-January with a radiant near Coma Berenices. Suzuki et al. (1994b) also published data from a multi-station study of the 1993 Perseid shower, providing orbital elements for 34 Perseids. Suzuki et al. (1993) provided a study of the $\eta$ Aquarid shower at television magnitudes.

Single station observation techniques were employed by a number of authors. Hawkes and Fleming (1995) determined a rate profile for the Perseid shower at television magnitudes. Molau (1995a) reported on single station observations for the Quadrantid and Perseid showers, providing detailed radiant information, as well as an investigation of time clustering in the Perseid data.

Television observations continued to play a role in defining the physical structure and chemical composition of meteoroids. Shadbolt and Hawkes (1995) reported on the apparent absence of wake in faint sporadic meteors, indicative of either a very narrow grain size spectrum or an absence of fragmentation. Borovička and Boček (1995) have used television techniques in the study of meteor spectra.

Molau (1995b) compared video based meteor magnitudes with those estimated by visual observers, finding that on average visual observers underestimate the brightness of meteors by about one-half magnitude, with little velocity or brightness correlation. Fujiwara et al. (1995) employed intensified video methods in conjunction with a middle and upper atmospheric radar system, providing a relation between 
radar echo duration and meteor magnitude. Meisel et al. (1995) combined video with a variety of other observational techniques in the study of a -10 magnitude fireball. Several papers (Brown et al., 1994; Beech et al., 1995; Ceplecha et al., 1996) reported on analysis of the spectacular Peekskill meteorite fireball, which was recorded by both high resolution still camera and at least 15 video cameras. This provides the most detailed atmospheric fragmentation record ever of a meter-sized meteoroid.

The MOVIE software developed by Sirko Molau in Germany for the analysis of video meteor data is documented in Molau (1995c). A proposed automated television detection system is described by Gural (1995).

Sirko Molau has provided an important service to the professional and amateur television meteor community by setting up a comprehensive WWW page with background information, sample images, analysis techniques, reference lists, and the complete text of a number of papers. The URL is: http://www.tuchemnitz.de/ smo/imo/video/video.html

\section{METEOR SHOWERS AND METEOROID STREAM EVOLUTION P. BROWN AND J. JONES}

The enhanced activity of the Perseid shower has been observed visually (Koschack et al. 1993; Jenniskens, 1995; Belkovich et al. 1995), by radar (Cevolani et al. 1995; Šimek and Pecina, 1995) and with TV (Hawkes and Fleming, 1995). Lindblad and Porubčan (1994), using photographic data, have been able to trace the activity of the new peak back almost 50 years. Wu and Williams (1993) and Williams and $\mathrm{Wu}$ (1994) from a numerical study have reproduced many of the gross features of the stream assuming ejecta in 1862 but there is still a discrepancy between the observed and predicted nodal longitude of the new peak. Wu and Williams (1995b) have investigated the mean motion resonances in the stream from the distribution of semi-major axes in photographic Perseid data. Harris et al (1995) have also modeled the stream and find it to be remarkably stable and about 105 years old. Harris and Hughes (1995) were unable to find significant correlation between semi-major axis and mass. Lindblad and Porubčan (1995) have studied the radiant area and drift for the shower.

Steel (1995) has devised a new criterion for investigating the reality of asteroid - meteoroid streams associations and finds clear evidence only for the association between the Geminids and 3200 Phaethon. Gorbanev and Kramer (1993) have presented an analytic model for asteroidal meteoroid swarms which they apply to the Geminids. Jopek, (1993b) and Porubčan et al. (1995b) have studied meteor stream associations using the D-criterion but it is becoming clear that the orbital evolution of meteoroids in older streams needs to be incorporated into meteor stream identification procedures and that D-criterion is often inadequate.

Šmek (1994) and Sidorov et al. (1994) find mass-dependent times of maximum activity in radar observations of the 1985 Giacobinids. Wu and Williams (1995a) show that strong returns are associated with material ejected at the cometary apparition closest to the storm. Lindblad et al. (1994) have determined an accurate photographic orbit for the $\eta$ Aquarids.

Interest in the Leonid stream has grown considerably in anticipation of the 1998 return of $109 \mathrm{P} /$ TempelTuttle. Enhanced activity of the stream has been detectable in visual observations (Brown, 1994; Brown and Rendtel, 1995; Jenniskens, 1996) and radar observations (Foschini et al., 1994). Calculations by Wu and Williams (1996) indicate no enhanced activity is to be expected from the shower in the late 1990s.

Williams and $\mathrm{Wu}(1993)$ have found a possible association between the Quadrantids and C/1490 Y1 while Ohtsuka et al. (1995) have detected the effects of Jovian perturbations on the orbit of the stream. Evans and Steele (1995) have analyzed visual and photographic observations of the 1992 Quadrantid return.

Porubčan et al. (1995a) report observations of the Lyrid stream by radar in 1994 and computations by Arter and Williams (1995) have failed to explain the past Lyrid outbursts.

Asher and Steel (1995), Ziolkowski, (1995) and Steel and Asher (1996) have argued that the Taurid stream and its possible complex of attendant NEAs may be the result of the breakup of a large comet in the recent past.

Kresak (1993), Beech et al. (1995c), and Jenniskens, (1995) successfully predicted an outburst of the $\alpha$ Monocerotids in 1995 and observations of that outburst (Rendtel et al, 1996) indicate that Kresak's identification of C/1943 W1 as the parent is probably incorrect. Elford et al. (1994) reported an outburst in radio-meteor activity the June Librids. 
The detailed analyses of visual observations of the annual streams by both Jenniskens (1994) and Rendtel et al. (1996) show the increasingly important role of amateurs to meteor science.

\section{METEOROID ORBITS D.I. STEEL}

The major development in this area in the last several years has been the operation of a new meteor radar in New Zealand (Baggaley et al. 1994; Baggaley, 1995). Over 400,000 orbits have been determined using that system, compared to the total of about 69,000 available at the IAU Meteor Data Center (IAU MDC) in Lund, Sweden (Lindblad 1995a). Although the data from New Zealand are currently being exploited by the researchers responsible for running the radar, it is to be anticipated that they will eventually be made available to the wider community through the IAU MDC.

Another notable achievement of the past few years has been the measurement of the heliocentric orbit of a meteorite-dropping body (Brown et al. 1994, Ceplecha et al. 1996), the fourth such meteoroid to have its orbit determined.

Around the world several groups have made measurements of limited numbers of new meteoroid orbits using small camera or TV techniques, for example in Holland by Betlem et al. (1993), and in Japan by Ueda and Fujiwara (1993); see also Lindblad et al. (1994). Photographic observations of fireball orbits have also continued, the European Network being particularly worthy of mention (Spurný, 1994, 1995). Pecina (1994) has discussed how meteoroid orbits are calculated, given the raw observations, and his refinements are of particular importance when high-precision individual measurements are available, as in fireball observations; on the other hand Gustafson and Adolfson (1996) find that radiative effects are particularly significant for fainter meteors. Observational data on fireballs detected by U.S. surveillance satellites are now being made available to the civilian community, allowing orbits to be derived (e.g., Tagliaferri et al. 1995).

The older meteoroid orbits archived in the IAU MDC are now being exploited more fully than ever, because of renewed interest spurred by (i) The increasing rate of discovery of possible meteoroid parents (Earth-crossing comets and asteroids); (ii) The development of new, computer-intensive, techniques for studying the orbital evolution of small solar system bodies, and hence possible linkages between multiplet showers and parent bodies (Steel, 1994); and (iii) The various planned spacecraft missions to near-Earth objects over the next decade or so. The data that are available from the IAU MDC were described by Lindblad and Steel (1994) and Lindblad (1995a). Steel (1996) provides a very extensive discussion of how the various orbits were determined, how they have been analyzed, and presents comparative orbit distribution plots for the various surveys that are archived.

There have been many studies completed in the last triennium making use of orbits obtained from the IAU MDC. Lindblad et al. (1994) selected orbits of $\eta$ Aquarid meteors to find the mean orbit of this Comet Halley-derived stream, whilst Lindblad et al. (1993) and Koseki (1993) searched for Leonids (linked with Comet Tempel-Tuttle). Lindblad and Porubčan (1994), Wu and Williams (1995b), Harris and Hughes (1995) and Harris et al. (1995) investigated the masses and orbits of Perseids amongst the photographic data; see also Hughes (1995). Rendtel (1993) searched for photographic orbits from the minor showers known as the $\delta$ Aurigids and the September Perseids, and Porubčan and Gavajdová (1994) for fireball streams amongst bright photographic meteors. Arter and Williams (1995) discussed the orbits of the April Lyrid shower (associated with Comet Thatcher), and another possible shower in early April. Turning to fainter optical meteors, Jopek (1993a) searched for streams amongst meteoroid orbits measured in Canada using TV techniques.

Jopek $(1993 \mathrm{~b}, 1995)$ has discussed variants upon the orbital similarity D-criterion, and how streams may be separated from the sporadic background. The limits that should be applied to the standard Dcriterion were investigated by Neslušan et al. (1995) and Porubčan et al. (1995). Steel (1995) discussed how orbital databases might be searched to look for associations between weak streams and Earth-crossing asteroids. Babadzhanov $(1995,1996)$ considered the particular case of (2329) Orthos, an octuple Earthcrossing asteroid, whilst Obrubov (1995) examined an octuple Earth-crossing meteoroid stream, one of the resultant showers being the $\kappa$ Cygnids, which were investigated by Lindblad (1995b). Gavajdová (1995) examined various fireball streams, looking for associations with Earth-crossing asteroids. Spurný (1993) looked for Geminids amongst photographic meteor (and fireball) orbits, that shower being apparently linked with (3200) Phaethon, and Williams and Wu (1993) also looked for Geminid orbits.

Regarding the overall orbit and radiant characteristics of the sporadic population, Andreev et al. 
(1994) studied various parameters of the data available from the IAU MDC, and also their own radar at Kazan. Jones and Brown $(1993,1994)$ plotted the radiant distributions for various orbit survey data from the IAU MDC, having removed the stream meteoroids so as to leave only the sporadics.

Hajdukova (1993) examined the IAU MDC photographic orbits to see whether there is any evidence of hyperbolic (interstellar) meteoroids. Her answer was in the negative, for such large meteoroids. Taylor et al. $(1994,1996)$, using the recent New Zealand radar data, which pertain to much smaller particles, found positive evidence for meteoroids arriving from interstellar space, these originating from two or three discrete sources in the Sun's neighbourhood.

The fact that the double-humped speed distribution obtained in all meteoroid surveys has a different form, dependent upon the program in question, has been a long-term problem usually ascribed to selection effects (Elford et al. 1995). Most works which have required a speed distribution of meteoroids as an input parameter have used that derived from the Harvard Radar Meteor Project of the 1960's. Taylor (1995) has now shown that a numerical mistake made when those data were being analysed led to the distribution derived being seriously in error, the effect being most pronounced at the high velocity end of the distribution. Elford et al. (1995) used Taylor's results to show how, after this correction is made, the distributions for various radar and optical surveys come more closely into agreement, although there is still some discrepancy.

Steel $(1994)$ and Williams $(1995,1996)$ have reviewed the formation of meteoroid streams, including the orbital distributions produced, whilst Gustafson (1994) has discussed the physical processes which affect the orbits of meteoroids and interplanetary dust in space.

Finally, it should be noted that observations of meteoroid orbits are no longer limited to objects detected by means of their interaction with the atmosphere. The current IAU definition of the terms meteoroid and asteroid did not anticipate the stage being reached whereby objects as small as 10 metres might be detected in space, leading Beech and Steel (1995) to argue for the term meteoroid being defined as a solid object in space between 100 microns and 10 metres in size; smaller particles are dust, whilst larger refractory (non-cometary) objects are asteroids. The Spacewatch telescope has been used to detect several objects in cis-lunar space which are smaller than a few tens of metres in size, a few being possibly as small as 5 metres (Rabinowitz 1993; Scotti 1994; Gehrels and Jedicke 1996). These smaller objects, for which heliocentric orbits are usually determined, are therefore large meteoroids, or small asteroids. On the other hand, downward looking satellite sensors, covering a large fraction of the globe, are now providing information on the very bright fireballs produced by incoming objects 10 metres or more in size (Tagliaferri et al. 1995).

\section{DUST CHARACTERISTICS I. MANN AND E. GRÜN}

Experimental results on cosmic dust particles were mainly achieved with the twin dust detectors on the Ulysses and Galileo spaceprobes. During its approach to Jupiter in 1992, Ulysses detected bursts of dust grains and similar streams were detected by Galileo en route to Jupiter (Grün et al., 1992). Particles' impact speeds to the detector were greater than $20 \mathrm{~km} / \mathrm{s}$, their masses ranged from $10^{-13}$ to $10^{-16} \mathrm{~g}$ and their durations varied between several hours and three months. The arrival directions strongly suggest that dust streams originate in the Jovian system. Suggested sources are Jupiter's gossamer ring or the volcanoes on its moon Io (Grün et al. 1996). Several authors investigated the motion of dust particles in the gravitational and magnetic fields of Jupiter (Hamilton et al. 1993), the escape of dust from the Jovian system by electromagnetic interaction (Hamilton et al.1993, Horanyi et al. 1993), or possible periodicties in the streams (Horanyi et al.,1993). Ulysses also observed a flux of micrometre-sized dust particles with masses between $10^{-15}$ and $10^{-11} \mathrm{~g}$, moving with velocities higher than $26 \mathrm{~km} / \mathrm{s}$ along retrograde orbits. This detection was supported by Galileo results (Grün et al., 1994). The most probable explanation is that these particles are interstellar dust sweeping through the Solar System. Further analysis has been made to find out more about arrival directions and motion of these particles in the heliosphere (Gustafson et al. 1993, Hamilton et al. 1995). Ulysses passed the Sun's south pole in September 1994, penetrated the ecliptic plane in March 1995 and will continue its high latitude orbit for several years. Galileo entered its Jupiter orbit in December 1995, and further encounters with Callisto, Europa, and Ganymede will follow.

As far as the structure of the Zodiacal cloud is concerned, attempts have been made for a very detailed description (Divine 1993, Divine et al. 1994). The existence of several rings of enhanced dust 
concentration was suggested as a consequence of orbital trapings (Brownlee 1994, Dermott et al. 1994) and a suggested ring close to the Earth orbit could be identified in the COBE infrared data (Reach et al. 1995). The comparison of parameters of the IRAS dust bands with the Ulysses measurments showed that the dust bands have no significant component of submicron sized dust grains, which may be important for a further understanding of the collisional formation of the dust bands (Mann et al. 1996). Still puzzling is the nature of possible dust components at high latitudes above the ecliptic plane, which would explain the existence of dust above the solar poles in the solar corona (Mann 1994). Further information of dust fluxes may be obtained from the analysis of Doppler shifts of Fraunhofer lines in the Zodiacal light as discussed in Mukai and Mann (1993).

Theoretical studies have been made with respect to the dust dynamics under the influence of solar radiation pressure, solar wind (Banaskiewicz et al. 1994, Fahr et al. 1995, Klacka 1994, Scherer and Banaskiewicz 1994) and Lorentz forces. The formation of Martian dust rings, for instance was investigated under influence of radiation pressure forces and the influence of the gravity field based on the oblateness of the planet (Ishimoto and Mukai 1995, Hamilton 1996, Ishimoto 1996). Calculations of solar of radiation pressure forces have been performed based on assumptions of irregularly shaped particles of asteroidal, cometary and interstellar origin (Wilck and Mann 1996). In addition the gas drag forces have now been modelled for irregularly shaped particles (Nakamura et al. 1994). A new cometary dust emission model based on rigorous Keplerian dynamics has been developped by Fulle et al. (1995). The model was used to fit data coming from Giotto observations of $\mathrm{P} / \mathrm{Halley}$ and the power index of the differential size distribution of -3.5 and a gas to dust ratio of 4 resulted from the best fitting procedure.

For a further understanding of the properties of dust, studies on different carbon based materials as cosmic analogues produced in the laboratory were performed using different experimental techniques like Raman spectroscopy, Scanning and Transmission Electron Microscopy (SEM and TEM), optical gap analysis, microcombustion calorimetry as well as extiction measurments (Colangeli et al. 1994, Stephens et al. 1995). The spectral range of observations has been extended towards the microwave range (Mennella et al. 1995). The comparison of laboratory spectral measurements with cometary observations (Colangeli et al. 1995) revealed that spectral variations can be interpreted in terms of intrinsic and/or evolutionary differences.

\section{TEKTITES \\ C. KOEBERL}

Research on tektites and other materials related to impact cratering continued to be of great importance in the last few years, with events that marked the Cretaceous-Tertiary (K-T) boundary remaining in the forefront of research. Chaussidon et al. (1994) have shown that the sulfur in the yellow glasses occurs in the form of sulfate, which is not compatible with a volcanic source. Koeberl et al. (1994), using Re-Os isotope systematics, found evidence for a small meteoritic component in the Haitian glasses. Some earlier measurements of the iron oxidation state of the Haitian glasses have yielded high contents of Fe3+, but more detailed measurements have shown that high Fe3+ values are only present in an alteration rind, while the cores of the glasses show an $\mathrm{Fe} 3+/ \mathrm{Fe} 2+$ ratio of about 0.03 (Senftle, 1993), which is identical to values known from tektites. Thus, it was concluded that the Haitian glasses are of impact origin, and certainly not of volcanic origin. High precision age determinations on the Haitian glasses and impact melt from the Chicxulub crater have shown that both material are identical in age to each other and with the K-T boundary, at $65 \mathrm{Ma}$. From isotope geochemical evidence linking melt rocks from the Chicxulub impact crater (Koeberl, 1993a) and the Haitian impact glasses (Blum et al., 1993), it has to be concluded that a large impact event occurred at the K-T boundary, which distributed huge amounts of glass and other impact debris around the world.

In more traditional tektite studies, significant progress has been made with regard to identifying the source crater of the North American tektite strewn field. Poag et al. (1994) found geophysical evidence that there is actually a $85-90 \mathrm{~km}$ diameter crater structure buried underneath the lower Chesapeake Bay; Koeberl et al. (1996) confirmed the existence of the Chesapeake Bay impact structure from shock metamorphic studies, and provided further evidence that this structure, which is $35 \mathrm{Ma}$ old, may indeed be the North American tektite source crater.

The source crater of the Australasian tektite strewn field remains unknown, although a new proposal was published by Hartung and Koeberl (1994), namely that Lake Tonle Sap in Central Cambodia may be the remnant of this source crater. Koeberl (1993b) and Schmidt et al. (1993) found enrichments of 
siderophile elements in microtektite-baring layers of the Australasian tektite strewn field. The discovery of the first Muong Nong type georgiaite was reported by Glass et al. (1995). Matsuda et al. (1993) investigated the noble gases dissolved within tektites and found a composition that is essentially identical to that of the terrestrial atmosphere. Regarding the origin of tektites, while O'Keefe (1994) maintains that there is evidence for a lunar origin, further confirmation of a terrestrial impact origin was discussed by Koeberl (1994), Taylor and Koeberl (1994), and Chaussidon and Koeberl (1995).

\section{METEORS AND AERONOMY}

W.J. BAGGALEY

The thermalizing interaction between ablated meteoric species and the atmosphere has been examined by Jones (1995a) who performed a simulation of the collision process for a non-ionizing progression. The significant result is that a non-Gaussian distribution of the thermalized plasma is produced having implications for a correct interpretation of radio-meteor echo data: both the effective initial radius and the under/over-dense conditions are affected.

Following the initial expansion, the dispersal of meteoric material into the ambient atmosphere, though largely controlled by the molecular process of ambipolar diffusion, $D_{a}$, is severely affected by other factors. Elford (1993) giving illustrative height vs $D_{a}$ data drew attention to the effect of diurnal and seasonal changes in the atmospheric density gradients. Using a Middle-Upper Atmosphere radar with high directional precision, Tsutsuni et al. (1994) using the high signal-to-noise echo data base were able to extract structure in the $D_{a}$ height profile and reveal fluctuations over a scale of periods in $D_{a}$ and hence fluctuations in temperature associated with horizontal wind field patterns and so deduce gravity wave characteristics.

Of fundamental importance is the exact form of the dependence of $D_{a}$ on temperature. Jones $1995 \mathrm{~b}$ drew attention to the inadequacy of the kinetic approach arguing that, rather than a purely kinetic description for molecular interaction during the diffusion process, long range Coulomb forces are dominant, a simple mean-free-path parameter being inappropriate. That treatment suggests a form of $D_{a} \sim T / \rho$ rather than $D_{a} \sim T^{0.5} / \rho$. Use of the correct form is clearly important: scale-height determinations are affected because the overall temperature gradients above the mesopause are appreciable; and the analysis in terms of temperature fluctuations (e.g. Tsutsuni et al.1994) need modification. Jones (1995b) also formally demonstrated that the observed echo decay rate will be independent of the exact (Gaussian or otherwise) form of the initial (under-dense) ionization radial profile.

During diffusive dispersion of meteor species chemical reactions can occur. Following earlier work on the association beween ozone concentrations and the life-time of meteoric ionization, Šimek (1993) using the results from many years of Perseid data examined the sunrise ozone effect (see also Cevolani 1993). Similar echo duration distributions were presented for sporadics showing the diural and seasonal influences by Šmek (1995) (see also Jones and Šimek 1995). This technique may prove valuable for long-term monitoring of lower thermosphere ozone.

Elford (1993) drew attention to the possible influence of Faraday Rotation (due to the phase difference between the two magnetoionic components propagating through the under-lying ionization) in radarmeteor work. Because of the polarization effects, interpretation of (particularly daytime) data would be adversly affected. Conversly, by using crossed-polarisation antennas this phenomenon could be employed to measure lower E-region electron densities (Taylor and Elford 1996).

From their production at $90-110 \mathrm{~km}$, meteoric species evolve under the action of dynamical and photo-chemical proceses to produce ionospheric sporadic $\mathrm{E}$ layers and both neutral and ionized $\mathrm{Mg}, \mathrm{Fe}$ and $\mathrm{Na}$ layers in the meteor region as well as a general population extending up to the $\mathrm{F}$ region. Work has continued on the detection and modelling of these enhancements (Alpers et al. 1994, Gardner et al. 1995, Joiner and Aikin 1996, McNeil et al. 1996).

Both large gain MF radars (Chapin and Kudeki 1994) and UHF incoherent scatter facilities (e.g. Pellinen-Wannberg and Wannberg 1994) have shown potential for the examination of plasma parameters; instabilities, density and temperature in meteor trains (in addition to their role as atmospheric motion indicators). 


\section{References}

Adolfsson L.G., Gustafson B.A.S., 1994, Planet. Space Sci., 42, 593-598.

Adolfsson L.G., Gustafson B.A.S., Murray C.D., 1996, Icarus, 119, 144-152.

Alpers M., Hoffner J., von Zahn U., 1994, J. Geophys. Res., 99, 14971-14985.

Andreev V.V., Belkovich O.I., Evdokimov O.I., Suleymanova S.L., 1994, Planet. Space Sci., 42, 785-790.

Andreev V.V., Belkovich O.I., Filimonova T.K., Sidorov V.V., 1993, in Stohl \& Williams, 157-160.

Arter T., Williams I.P., Mon. Not. Roy. Astron. Soc., 277, 1087-1096.

Asher D.J., Steel D.I., 1995, Earth, Moon, and Planets, 68, 155-164.

Babadzhanov P.B., 1994, in Milani et al., pp. 45-54.

Babadzhanov P.B., 1995, Earth, Moon, and Planets, 68, 165-170.

Babadzhanov P.B., 1996, Earth, Moon, and Planets, 72, 305-310.

Baggaley W.J., 1995, Earth, Moon, and Planets, 68, 127-139.

Baggaley W.J., Bennett R.G.T., Steel D.I., Taylor A.D., 1994, Quart. Jl. R. Astron. Soc., 35, 293-320.

Baggaley W.J., Taylor A.D., Steel D. I., 1993a, in Stohl \& Williams, 53-56.

Baggaley W.J., Taylor A.D., Steel D. 1., 1993b, in Štohl \& Williams, 245-248.

Baguhl M. et al., 1995, Space Science Rev., 72, 471-476.

Baguhl M. et al., 1993, Planet. Space Sci., 41, 1085-1098.

Banaskiewicz M., Fahr H.J., Scherer K., 1994, Icarus, 107, 358-374.

Beech M. et al.,1995b, Earth, Moon, and Planets, 68, 189-197.

Beech M., Brown P., Jones J., 1995a, Earth, Moon, and Planets, 68, 181-188.

Beech M., Brown P., Jones J., 1995c, Quart. Jl. R. Astron. Soc., 36, 127-152.

Beech M., Steel D., 1995, Quart. Jl. R. Astron. Soc., 36, 281-284.

Belkovich O.I. et al., 1995, Astron. Vest., 29, 542-546.

Bellot Rubio L.R., 1995, Astron. Astrophys., 301, 602-608.

Betlem H., ter Kuile C.R., de Lignie M.C., 1993, in Stohl and Williams, 161-163..

Borovička J., 1993, Astron. Astrophys., 279, 627-645.

Borovička J., 1994a, Astron. Astrophys. Suppl. Ser., 103, 83-96.

Borovička J., 1994b, Planet. Space Sci., 42, 145-150.

Borovička J., 1994c, In: 75 Years of Hirayama Asteroid Families, Y. Kozai, R.P. Binzel, T. Hirayama (eds.), ASP Conf. Ser. $63,186-191$.

Borovička J., Boček J., 1995, Earth, Moon, and Planets, 71, 237-244.

Borovička J., Spurný P., 1996, Icarus, 121, 484-510.

Borovička J., Spurný P., Keclíková J. 1995, Astron. Astrophys. Suppl. Ser., 112, 173-178.

Borovička J., Zamorano J., 1995, Earth, Moon, and Planets, 68, 217-222.

Borovizka J. et al., 1996, Astron. Astrophys., 306, 995-998.

Bronshten V.A., 1994, Astron. Vest., 28, 118-124.

Brown P., 1994, WGN, 22, 190-193.

Brown P. et al., 1994, Nature, 367, 624-626.

Brown P. et al., 1996, Meteoritics Planet. Sci., 31, 502-517.

Brown P., Rendtel, J., 1995, WGN, 23, 196-198.

Brownlee D.E., 1994, Nature, 369, 706.

Celnikier L.M., 1995, Am. J. Phys., 63, 524-535.

Ceplecha Z., 1994a, in Milani et al., pp. 343-356.

Ceplecha Z., 1994b, Astron. Astrophys., 286, 967-970.

Ceplecha Z., 1995, Earth, Moon, and Planets, 68, 107-126.

Ceplecha Z., 1996, Astron. Astrophys., 311, 329-332.

Ceplecha Z et al., 1995, Earth, Moon, and Planets, 72, 395-404.

Ceplecha Z., Spurný P., Borovička J., Kecliková J., 1993 Astron. Astrophys, 279, 615-626.

Cevolani G., 1993, in Stohl and Williams, 311-314.

Cevolani G., 1994, Planet. Space Sci., 42, 767-775.

Cevolani G. et al.,1995, Contr. Astron. Obs. Skalnate Pleso, 25, 33-38.

Cevolani G., Hajduk A., 1993, in Štohl \& Williams, 253-256.

Cevolani G., Hajduk A., Kingsley S.P.,1993a, in Stohl \& Williams, 257-260.

Cevolani G. et al., 1993b, Nuovo Cimento C, 16, 255-263.

Cervera M.A.., Elford W.G., Steel D.I., 1993, in Stohl \& Williams, 249-252.

Chapin E., Kudeki E., 1994, J. Geophys. Res., 99, 8937-8949.

Chaussidon M., Koeberl, C., 1995, Geochim. Cosmochim. Acta, 59, 613-624.

Chaussidon M., Sigurdsson H., Metrich N., 1994, in New Developments Regarding the KT Event and Other Catastrophes in Earth History: Houston, Lunar and Planetary Institute, 21-22.

Chevalier R.A., Sarazin C.L., 1994, Astrophys. J., 429, 863-875.

Colangeli L. et al, 1995, Astron. Astrophys., 293, 927-934.

Colangeli L., Mennella V., Stephens J.R., Bussoletti E., 1994, Astron. Astrophys., 284, 583-592.

Coradini M. et al., 1994, Planet. Space Sci., 42, 441-446.

Crawford D.A., Boslough M.B., Trucano T.G., Robinson A.C., 1994, Shock Waves, 4, 47-50.

de Lignie M, Jobse K., 1996, WGN, 24, 20-26.

Dermott S. F. et al., 1994, in Milani et al.,127-142.

Dermott S. F., Jayaraman S., Xu Y.L., Gustafson B.A.S., 1994, Nature, 369, 719-723.

Divine N., 1993, J. Geophys. Res., 98,17029-17048.

Divine N., Grün E., Staubach P., 1993, In Proc. First Europ. Conf. on Space Debris, ESA SD-01, 245-250.

Elford W.G., 1993, in Stohl \& Williams, 235-244.

Elford W.G., Cervera M.A., Steel D.I., 1994, Mon. Not. Roy. Astron. Soc., 270, 401-408. 
Elford W.G., Cervera M.A., Steel D.I., 1995, Earth, Moon, and Planets, 68, 257-266.

Evans S.J., and Steele C.D.C., 1995, J. Br. Astron. Assoc., 105, 83-88.

Fahr H.J., Scherer K., 1995, Astrophys. Space Sci., 225, 21-45.

Fahr H.J., Scherer K., Banaszkiewicz, M., 1995, Planet. Space Sci., 43, 301-312.

Field G.B., Ferrara A., 1995, Astrophys. J., 438, 957-967.

Foschini L., Cevolani G., Trivellone G., 1995, Niovo Cimento C, 18, 345-349.

Fujiwara Y., Ueda M., Nakamura T., Tsutsumi M., 1995, Earth, Moon, and Planets, 68, 277-282.

Fulle M. et al., 1995, Astron. Astrophys., 304, 622.

Gardner J.A. et al., 1995, Geophys. Res. Lett., 22, 2110-2122.

Gavajdová, M., 1995, Earth, Moon, and Planets, 68, 289-292.

Gehrels T., Jedicke R., 1996, Earth, Moon, and Planets, 72, 233-242.

Gorbanev, Y.M., Kramer E.N., 1993, Astron. Vest., 27, 102-108.

Grün E., 1994, in Milani et al., 367-380

Grün E. et al., 1995, Science, 268, 1016-1019.

Grün E. et al., 1995, Planet. Space Sci., 43, 971-999.

Grün E. et al.,1995, Nature, 381, 395-398

Grün E. et al.,1993, Nature, 362, 428-430.

Grün E. et al., 1995, Planet. Space Sci., 43, 941-951.

Grün E. et al., 1993, Astron. A strophys., 286, 915-924.

Grün E. et al.,1994, Geophys. Res. Lett., 21, 1035-1038.

Gural P., 1995, WGN, 23, 228-235.

Gustafson B.A.S.,1994, Ann. Rev. Earth Planet. Sci., 22, 553-595.

Gustafson B.A.S., Adolfson L.G., 1996, Earth, Moon, and Planets, 72, 327-332.

Hajduk A. et al., 1995, Planet. Space Sci, 43, 747-749.

Hajdukova M., 1993, in Stohl and Williams, 61-64.

Halliday I., Griffin A.A., Blackwell A.T., 1996, Meteoritics Planet. Sci., 31, 185-217.

Hamilton D. P., 1993, Icarus, 101, $244-264$.

Hamilton D.P., 1996, Icarus, 119,153-172.

Hamilton D. P.,Burns J.A., 1993, Science, 264, 550-553.

Harris N.W., Hughes D.W., 1995, Mon. Not. Roy. Astr. Soc., 273, 992-998.

Harris N.W., Yau K.C.C., Hughes D.W., 1995, Mon. Not. Roy. Astr. Soc., 273, 999-1015.

Hartung J.B., Koeberl C., 1994, Meteoritics, 29, 411-416.

Hawkes R.L., Fleming D.E.B., 1995, Earth, Moon, and Planets, 68, 303-310.

Horanyi M., Morfill G., Grün E., 1993, Nature, 363, 144-146.

Horanyi M., Morfill G., Grün E., 1993, J. Geophys. Res., 98, 21 245-21 251.

Hughes D.W., 1995, Earth, Moon, and Planets, 68, 31-70.

Ishimoto H., 1996, Icarus, 122, 153-165.

Ishimoto H., Mukai T.1994, Planet. Space Sci., 42, 691-697.

Jenniskens P., 1994, Astron. Astrophys., 287, 990-1013.

Jenniskens P., 1995a, WGN, 23, 84-86.

Jenniskens P., 1995b, Astron. Astrophys., 295, 206-235.

Jenniskens P., 1996, Meteoritics Planet. Sci., 31, 177-184.

Joiner J., Aikin A.C., 1996, J. Geophys. Res., 101, 5239-5249.

Jones J., Brown P., 1993, Mon. Not. R. Astron. Soc., 265, 524-532.

Jones J., Brown P., 1994, Planet. Space Sci., 42, 123-126.

Jones J., Brown P., Webster A.R., Ellis K., 1994, Planet. Space Sci., 42, 123-126.

Jones J., Simek M., 1995, Earth, Moon, and Planets, 68, 329-38.

Jones W., 1995a, Mon. Not. Roy. Astron. Soc., 275, 812-818.

Jones W., 1995b, Annal. Geophysicae, 13, 1104-1106.

Jopek T.J., 1993a, in Stohl and Williams, 269-272.

Jopek T.J., 1993b, Icarus, 106, 603-607.

Jopek T.J., 1995, Earth, Moon, and Planets, 68, 339-346.

Kalinichenko V.V., 1995, Kin. Fiz. Nebes. Tel , 11, no. 6, 55-69.

Keay C., 1995, Earth, Moon, and Planets, 68, 361-368.

Keay C.S.L., Ceplecha Z., 1994, J. Geophys. Res., 99, 13163-13165.

Klacka J., 1994, Earth, Moon, and Planets, 64, 55-58.

Klacka J., 1994, Earth, Moon, and Planets, 64, 95-98.

Klacka J., 1994, Earth, Moon, and Planets, 64, 125-132.

Knöfel A., 1995, Earth, Moon, and Planets, 68, 381-384.

Koeberl C., 1993a, Geology, 21, 211-214.

Koeberl C., 1993b, Earth Planet. Sci. Let., 118, 453-458.

Koeberl, C., 1994, in Geological Society of America Special Paper 293, 133-151.

Koeberl C. et al., 1994, Geochim. Cosmochim. Acta, 58, 1679-1684.

Koeberl C., Taylor S.R., 1994, Meteoritics, 29, 739-744.

Korlević K., Valdré G., 1994, Planet. Space Sci., 42, 673-675.

Koschack R., Arlt R.,Rendtel J., 1993, WGN, 21, 152-167.

Koseki M., 1993, in Stohl and Williams,173-176.

Kresak L., 1993, Astron. Astrophys., 279, 646.

Kruchinenko V.G., 1995, Astron. Vest., 29, 357-359.

Lebedinets V.N., Galkina I.V., 1995, Astron. Vest., 29, 72-77.

Linblad B.A., 1995a, Earth, Moon, and Planets, 68, 405-408.

Lindblad B.A., 1995b, Earth, Moon, and Planets, 68, 397-404. 
Lindblad B.A., Ohtsuka K., Shirakawa K., 1994, Planet. Space Sci., 42, 113-117.

Lindblad B.A., Porubčan V., Stohl, J. 1993, in Stohl and Williams, 177-180.

Lindblad B.A., Porubcan V., 1994, Planet. Space Sci., 42, 117-123.

Lindblad B.A., Porubcan V., 1995, Earth, Moon, and Planets, 68, 409-418.

Linblad B.A., Steel D.I., 1994, in Milani et al., 497-501.

MacLow M.-M., Zahnle K., 1994, Astrophys. J., 434, L33-L36.

Mann I., 1994, Space Sci. Rev., 72, 477-482.

Mann I., Grün E., 1994, Adv. Space Res., 17, 99-102.

Mann I., Grün E., 1994, Planet. Space Sci., 43, 827-832.

Mann I., Grün E., Wilck M., 1996, Icarus, 120, 399-407.

Mann 1. et al., 1994, Astron. Astrophys., 291, 1011-1018.

Mann I., Scherer K., 1995, EOS Trans. AGU, 76 (46), F 338.

Matsuda J. I., Matsubara K., Koeberl, C., 1993, Meteoritics, 28, 586-589.

Mawrey R.S., Broadhurst A.D., 1993, Radio Sci., 28, 415-427.

Mawrey R.S., Broadhurst A.D., 1993, Radio Sci., 28, 428-440.

McCord T.B. et al., 1995, J. Geophys. Res., 100, 3245-3249.

Mclnnes C.R., 1995, Mon. Not. R. Astron. Soc., 274, 110-114.

McNeil W.J., Lai S.T., Murad E., 1996, J. Geophys. Res., 101, 5251-5259.

Meisel D.D. et al.,1995, Icarus, 116, 227-254.

Mennella V. et al., 1995, Astrophys. J., 444, 288-292.

Mennella V. et al., 1995, Planet. Space Sci., 43, 1217-1222.

Mennella V. et al., 1995, Astrophys. J. Suppl., 100, 149-158.

Mennella V. et al., 1996, Astrophys. J. Lett., 464, L1.

Mennella V., Monaco G., Colangeli L., Bussoletti E., 1995, Carbon, 33, 115.

Milani A., Di Martino M., Cellino A., eds., 1994, Asteroids, Comets, Meteors 1999, IAU Symp. No. 160, Kluwer Acad. Publ.

Molau S., 1995a, WGN, 23, 217-224.

Molau S., 1995b, WGN, 23, 225-228.

Molau S., 1995c, International Meteor Conference 1994 (ed. by A. Knöfel and P. Roggemans), IMO Publication, $51-61$.

Mukai H., Mann I., 1993, Astron. Astrophys., 271, 530-534.

Nakamura R., Kitada Y., Mukai T., 1994, Planet. Space Sci., 42, 721-726.

Nemtchinov I.V., Popova O.P., Shuvalov V.V., Svetsov V.V., 1994, Planet. Space Sci., 42, 491-506.

Nemtchinov I.V., Popova O.P., Svetsov V.V., Shuvalov V.V., 1995, Astron. Vest., 29, 155-173.

Neslušan L., Svoreñ J., Porubčan V., 1995, Earth, Moon, and Planets, 68, 427-433.

Novikov G.G., Pecina P., Konovalova N.A., 1996, Astron. Astrophys., 306, 991-994.

Obrubov Yu.V., 1995, Earth, Moon, and Planets, 68, 443-449.

Ohtsuka K., Yoshikawa M., Watanabe J-1., 1995, Pub. Astron. Soc. Japan, 47, 477-486.

O'Keefe J.A., 1994, Meteoritics, 29, 73-78.

Pecina P., 1994, Planet. Space Sci., 42, 677-683.

Pellinen-Wannberg A., Wannberg G., 1994 J. Geophys. Res., 99, 11379-11390.

Pellinen-Wannberg A., Wannberg G., 1996, J. Atmos. Terr. Phys., 58, 495-506.

Poag, C. W., Powars, Poppe, L. J., Mixon, R. B., 1994, Geology, 22, 691-694.

Porubčan V., Cevolani G., Stohl J., 1993, Nuovo Cimento C, 16, 205-209.

Porubčan V., Gevolani G., 1994a, Nuovo Cimento $C, 17,243-248$.

Porubčan V., Gavajdová, M., 1994, Planet. Space Sci., 42, 151-155.

Porubčan V., Hajduk A., Cevolani G., 1994b, Nuovo Cimento C, 17, 249-253.

Porubčan V. et al., 1995a, Earth, Moon, and Planets, 68, 465-469.

Porubčan V., Svoreñ, J., Neslušan, L., 1995b, Earth, Moon, and Planets, 68, 471-478.

Rabinowitz D.L., 1993, Astrophys. J., 407, 412-427.

Rajchl J. et al., 1995, Earth, Moon, and Planets, 68, 479-486.

Reach W.T. et al., 1995, Nature, 374, 521-523.

Rendtel J., 1993, in Stohl and Williams, 185-188.

Rendtel J., Arlt R., McBeath A., 1995, Handbook for Visual Meteor Observers, International Meteor Organization.

Rendtel J. Brown P., Molau S., 1996, Mon. Not. Roy. Astr. Soc., 279, L31-L36.

Revelle D.O., Ceplecha Z., 1994, Astron. Astrophys., 292, 330-336.

Revelle D.O., Whitaker, R.W., 1995, LAUR-95-4121, Los Alamos preprint, 7 pp.

Ridley H.B., 1994, J. Br. Astron. Assoc., 104, 32-35.

Rogers L.J., Keay C.S.L., 1993, in Stohl \& Williams, 273-276.

Scherer, K., Banaszkiewicz, M., 1994, Celestial Mechanics, 59, 375-387.

Schmidt G., Zhou L., Wasson J.T., 1993, Geochim. Cosmochim. Acta, 57, 4851-4859.

Scotti J., 1994, in Milani et al., 17-30.

Sekanina Z., 1993, Science, 262, 382-387.

Senftle F. E. et al.,1993, Lunar and Planetary Science, XXIV, 1275.

Shadbolt L., Hawkes R.L., 1995, Earth, Moon, and Planets, 68, 493-502.

Sidorov V.V., Stepanov A.M., Sulejmanov N.I., 1994, Astron. Vest., 28, 140-144.

Śimek M.,1993, in Stohl \& Williams, 277-280.

Simek M., 1994a, Astron. Astrophys., 284, 276-280.

Simek M., 1994b, Planet. Space Sci., 42, 141-143.

Simek M., 1995, Earth, Moon, and Planets, 68, 545-553.

Simek M., Pecina, P., 1995, Earth, Moon, and Planets, 68, 555-561.

Smirnov V.A., 1995, Earth, Moon, and Planets, 68, 515-522.

Spurný P., 1993, in Stohl and Williams, 193-196.

Spuný P., 1994, Planet. Space Sci., 42, 157-162. 
Spurný P., 1995, Earth, Moon, and Planets, 68, 529-537.

Steel D.I., 1994, in Milani et al., 111-126.

Steel D.I., 1995, Earth, Moon, and Planets, 68, 13-30.

Steel D.I., 1996, Space Sci. Rev., in press.

Steel D.I.,Asher D.J., 1996, Mon. Not. Roy. Astr. Soc., 280, 806-822.

Stephens J.R. et al., 1995, Planet. Space Sci., 43, 1241-1246.

Suzuki K., Akebo T., Suzuki S., Yoshida T.,1993, WGN, 21, 214-215.

Suzuki K., Akebo T., Suzuki S., Yoshida T.,1994a, WGN, 22, 50-51.

Suzuki K., Yoshida T., Suzuki K., Akebo T., 1994b, WGN, 22, 137-139.

Svetsov V.V., 1995, Astron. Vest., 29, 331-340.

Svetsov V.V., Nemtchinov I.V., Teterev A.V., 1995, Icarus, 116, 131-153.

Stohl J., Williams I.P., eds. 1993, Meteoroids and their Parent Bodies, Slovak Academy of Sciences, Bratislava, Slovak Republic.

Tagliaferri E. et al., 1994, in Hazards due to Comets and Asteroids, T. Gehrels (ed.), The University of Arizona Press, 199-220.

Tagliaferri E., Spalding R., Jacobs C., Ceplecha Z., 1995, Earth, Moon, and Planets, 68, 563-572.

Takata T, O'Keefe J.D., Ahrens T.J., Orton G.S., 1994, Icarus, 109, 3-19.

Taylor A.D., 1995, Icarus, 116, 154-158.

Taylor A.D., Baggaley W.J., Bennett R.G., Steel D.I., 1994, Planet. Space Sci., 42, 135-140.

Taylor A.D., Baggaley W.J., Steel D.I., 1996, Nature, 380, 323-325.

Taylor A.D, Elford W.G., 1996, J. Atmos. Terr. Phys. (in the press).

Tsutsuni.M, Tsuda.T, Nakamura.T, and Fukao.S, 1994, Radio Sci., 29, 599-610.

Ueda M., Fujiwara Y., 1993, in Stohl and Williams, 281-284.

Ueda M., Fujiwara Y., 1995, Earth, Moon, and Planets, 68, 585-603.

Wannberg G., Pellinen- Wannberg A., 1996, Radio Sci., 31, 497-518.

Watanabe J., 1993, in Stohl \& Williams, 197-200.

Wilck M., Mann I., 1996, Planet. Space Sci., 44, 493-499.

Williams I.P., 1995, Earth, Moon, and Planets, 68, 1-12.

Williams I.P., 1996, Earth, Moon, and Planets, 72, 321-326.

Williams I.P., Wu Z., 1993, Mon. Not. R. Astron. Soc., 262, 231-248.

Williams I.P., Wu Z., 1993, Mon. Not. Roy. Astr. Soc., 264, 659-664.

Williams I.P.,Wu Z., 1994, Mon. Not. Roy. Astr. Soc., 269, 524-528.

Wu Z., Williams 1.P., 1993, Mon. Not. Roy. Astr. Soc., 264, 980-990.

Wu Z., Williams I.P., 1995a, Planet. Space Sci., 43, 723-731.

Wu Z., Williams I.P., 1995b, Mon. Not. Roy. Astr. Soc., 276, 1017-1023.

Wu Z., Williams I.P., 1996, Mon. Not. Roy. Astr. Soc., 280, 1210-1218.

Zahnle K., MacLow M.-M., 1994, Icarus, 108, 1-17.

Zakharov N.S., Karpenko, V.A., 1993, Astron. Vest., 27, 95-98.

Zhou Q., Tepley C.A., Sulzer, M.P., 1995, J. Atmos. Terr. Phys., 57, 421-431.

Ziolkowski K., 1995, Earth, Moon, and Planets, 68, 647-651. 